\title{
ANALYSIS OF THE ADVERSE DRUG REACTIONS COLLECTED THROUGH ACTIVE SURVEILLANCE IN THE PHARMACOVIGILANCE UNIT OF A TERTIARY CARE HOSPITAL
}

\author{
ANAND M INGALE, PRATIBHA NADIG*, ANANYA CHAKRABORTY
}

Department of Pharmacology, Vydehi Institute of Medical Sciences and Research Centre, Bengaluru - 560 066, Karnataka, India. Email: drpratibhanadig@yahoo.co.in

Received: 23 March 2018, Revised and Accepted: 08 May 2018

\section{ABSTRACT}

Objectives: The objectives of the study were to analyze the various adverse drug reactions (ADRs) collected in the Pharmacovigilance Unit of Vydehi Institute of Medical Sciences and Research Centre with respect to their causality, severity, and preventability and also to identify the various risk factors, concomitant medications, and comorbid conditions with the occurrence of these events.

Methods: A prospective, non-interventional, observational, and cross-sectional study was carried out in the various clinical departments of Vydehi Institute of Medical Sciences and Research Centre from June 2014 to May 2015. The Classes of drugs, Organ system involved, Comorbid conditions associated and Concomitant drugs involved in causing ADRs were looked into. The assessment for causality and severity was determined by Naranjo and Modified Hartwig and Siegel scales, respectively. The data were compiled and subjected to descriptive statistical analysis.

Results: A total of 433 patients developing ADR reports were analyzed during our study period. Of these, 53.59\% were females. $75 \%$ of them were of adult age group. Antimicrobials and chemotherapy group showed the maximum ADRs. The skin and appendages (27.6\%) were the most affected organ system followed by the gastrointestinal system (22.8\%). Comorbid conditions were found in $76(20.1 \%)$ reports; of which diabetes (28.9\%) and hypertension (26.3\%) were maximum. 74 were serious reports. Maximum reports were probable and of mild severity.

Conclusion: Through active surveillance of the ADRs helps in early detection and prevention of all the possible adverse events associated with the usage of drugs and thereby provides a better health-care treatment to the patients.

Keywords: Adverse drug reaction, Causality, Serious reaction, Naranjo, Hartwig, Pharmacovigilance.

(c) 2018 The Authors. Published by Innovare Academic Sciences Pvt Ltd. This is an open access article under the CC BY license (http://creativecommons. org/licenses/by/4. 0/) DOI: http://dx.doi.org/10.22159/ajpcr.2018.v11i8.26138

\section{INTRODUCTION}

Adverse drug reactions (ADRs) form an important compounding factor in the management of any clinical conditions, constituting an important cause for the morbidity and mortality [1]. ADRs are the fourth leading cause of death [2]. They occur in 10-20\% of hospitalized patients [3]. The incidence of ADRs varies from $0.15 \%$ to $30 \%$ [4]. Serious ADRs account for 6-7\% of all hospital admissions [2]. A study in South India showed that ADRs accounted for $0.7 \%$ of total admissions, and $1.8 \%$ of ADRs resulted in death [5].

As most of these ADRs are preventable, a thorough knowledge about them helps in analyzing the pattern and severity of them in various clinical conditions, which, in turn, helps in reduction of the health-care cost [6].

Spontaneous reporting, a part of active surveillance, though theoretically the best method of ADR assessment, has not been an effective method due to a large percentage of under-reporting. Reporting of ADRs is only $3 \%$ of the global ADR occurrence [7]. Passive or stimulated reporting is by and large the most common method of ADR reporting. It is recommended by Pharmacovigilance Program of India. However, active surveillance through direct interaction with patients has been reported to be the most effective means to assess the ADRs prevailing in the society [8]. Our previous experience of active surveillance in a single department has clearly shown that active surveillance also improves spontaneous reporting [5].

Our review of literature has shown numerous studies with active surveillance. However, very few studies have been carried out to assess the association of factors such as comorbid conditions and concomitant medications with the occurrence of the ADRs, which may be playing a key role in their occurrences. The knowledge of the same will help in making the prescriber aware of the various possible adverse events associated with the use of drugs.

Hence, the present study was undertaken in various clinical departments of Vydehi Institute of Medical Sciences and Research Centre (VIMS and $\mathrm{RC}$ ) through active surveillance to analyze the different ADRs occurring in them.

\section{Research objectives}

The objectives are as follows:

1. To analyze the various ADRs collected in the Pharmacovigilance Unit of Vydehi Institute of Medical Sciences and Research Centre with respect to their causality, severity, and preventability.

2. To identify the various risk factors, concomitant medications and comorbid conditions with the occurrence of these events.

\section{METHODS}

A prospective, non-interventional, observational, and cross-sectional study for a period of 1 year from June 2014 to May 2015 was conducted at the various clinical departments of VIMS and RC after obtaining the approval of the Institutional Ethics Committee (VIEC/2016/APP/028).

Regular visits to the outpatient department and the inpatients of various clinical departments were carried out. Standard Central Drugs Standard Control Organization form [9] was used for reporting and analyzing the ADRs.

Each patient was interrogated only after obtaining their verbal consent. A detailed survey of the patient's complaints, treatment history and the 
various events that occurred after administering the drugs was done and documented. Any new and unusual events occurring after the drug administration were also interrogated. The collected reports were subjected to analysis and later submitted to our Pharmacovigilance Unit.

The activity was divided among two groups to reduce any chances of bias. One group was involved in collecting the data and the other in analyzing the collected data.

\section{The analysis of data was carried out as follows}

\section{Validity of the reports}

ADR report with an identifiable patient, identifiable drug, indication for the use of the drug, and proper dateswas considered valid and was included in our study [10].

\section{Demography}

The age of the patient was recorded and was grouped accordingly as pediatric, adult, or geriatric. The sex of the patient was noted.

\section{Drug Group and its classes}

Drug group along with its classinvolved in causing the reaction was recorded and categorized [11]

\section{Organ system involvement}

The organ systembeing affected in the reaction was recorded and categorized accordingly [12]

\section{Number of drugs in therapy}

Each of the reaction was looked in for the number of drugs prescribed for therapy and was categorized as reaction with monotherapy in case of reactions involving only one drug prescription and reactions with more than one drug prescribed were categorized as polytherapy reactions.

\section{Comorbid conditions}

Details of the various comorbid conditions (diabetes mellitus, hypertension, thyroid diseases, and so on) present in the patient likely to influence the occurrence of ADRs were surveyed and tabulated.

\section{Measures undertaken and the outcome measures}

Measures undertaken and outcome measures seen in the ADR were looked into and tabulated [13]

\section{Seriousness of the reactions}

Seriousness of the reactions was looked into and the reactions were classified as serious or non serious as per the World Health Organization guidelines [14]. In addition to this, the reasons for the seriousness of the reactions were also surveyed and tabulated.

\section{Expectedness of the reaction}

The expectedness of the reaction was analyzed by doing a literature search on the possible ADRs due to the causative drug and also from the summary of the product characteristics. The outcome of the reaction was cross-checked with all the possible outcomes that could occur and it was analyzed as to whether the outcome occurring in the reaction is an expected reaction or not [15].

\section{Risk factors associated with ADRs}

The cases were thoroughly looked into the possible risk factors such as smoking, alcohol consumption, history of allergy, age, and concomitant medications.

\section{Causality assessment}

Causality assessment was done by Naranjo et al. [16] scale and the reactions were categorized as probable, certain, possible, or unlikely depending on the scores obtained.

\section{Severity assessment}

Severity assessment was done by Modified Hartwig et al. [17] scale and the reactions were categorized as mild, moderate, or severe accordingly based on their scores.

\section{Statistical analysis}

The data were analyzed through descriptive statistics, and the values were expressed in numbers and percentages.

\section{RESULTS}

\section{Validity of the reports}

We encountered 433 patients developing ADRs. Out of these, 377 [85.15\%] were valid reports and were included in our study.

\section{Demography}

Of the 377 valid reports, 175 (46.41\%) were of males and 202 (53.59\%) were of females. The age group of the patients is depicted in Fig. 1. The adult group possessed the maximum ADRs

\section{Drug groups and classes}

Antimicrobial and chemotherapy group of drugs accounted for the maximum ADRs as depicted in Fig. 2.

\section{Organ system involvement}

The most affected organ system was the skin and appendages (27.6\%) as depicted in Fig. 3 .

\section{Number of drugs in therapy}

The monotherapy and polytherapy reports were 188 and 189, respectively, in our study.

\section{Comorbid conditions associated with ADRs}

On analyzing the comorbid conditions associated with the ADRs, we found that they were present in $76(20.1 \%)$ reports, of which diabetes $(28.9 \%)$ and hypertension $(26.3 \%)$ were the most common ones as depicted in Table 1.

\section{Measures undertaken and the outcome measures}

The most common measure undertaken was stoppage of the drug $(\mathrm{n}=276 ; 73.2 \%)$ whereas drug was continued in $71(18.8 \%)$ patients and $70(18.56 \%)$ cases, it was unknown.

With respect to the outcome measures, maximum were recovered $(\mathrm{n}=212$; 56.2\%) whereas 75 (19.89\%) were recovering, 64 (16.97\%) were continuing, and $26(6.89 \%)$ were unknown.

\section{Seriousness}

We encountered 74 (19.62\%) serious reports. The most common reason for seriousness was hospitalization-initial or prolonged as depicted in Fig. 4.

\section{Expectedness}

The literature search for all the possible ADRs possible with each drug was done and analyzed as to whether the particular ADR manifested is expected or not. We found that 290 (76.92\%) reports were expected outcomes whereas 97 (25.72\%) were unexpected.

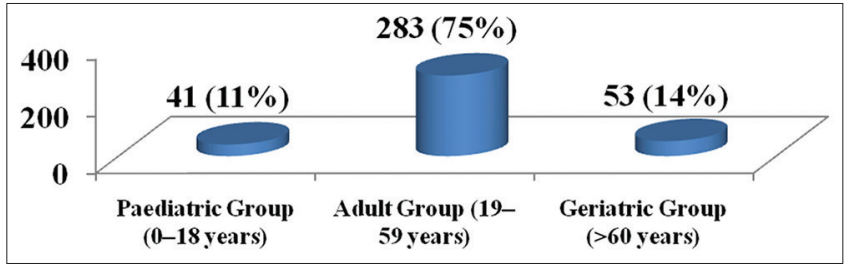

Fig. 1: Age groups of patients involved in adverse drug reactions 


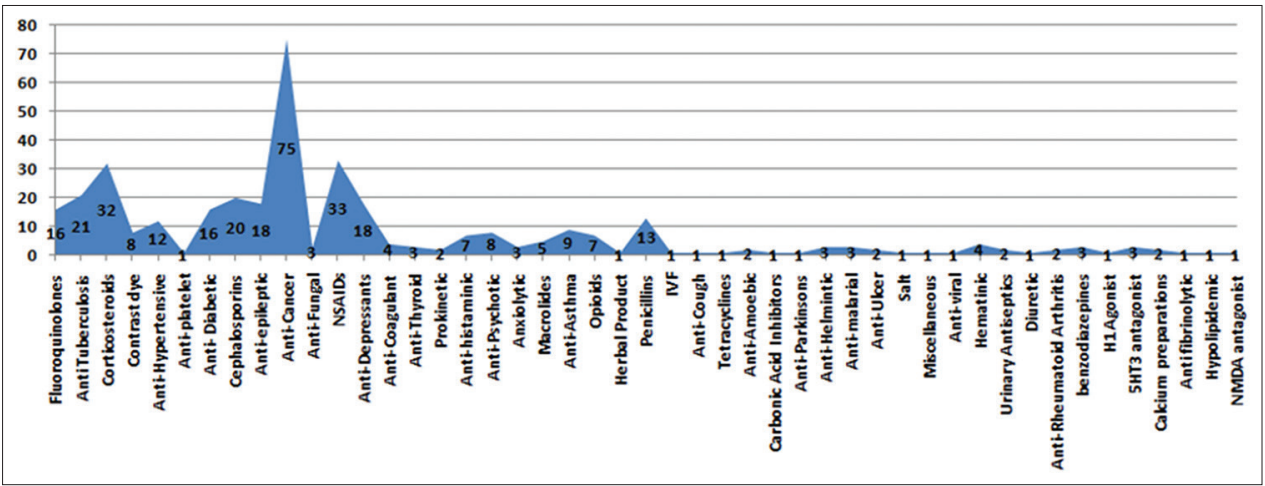

Fig. 2: Classes of drugs causing adverse drug reactions

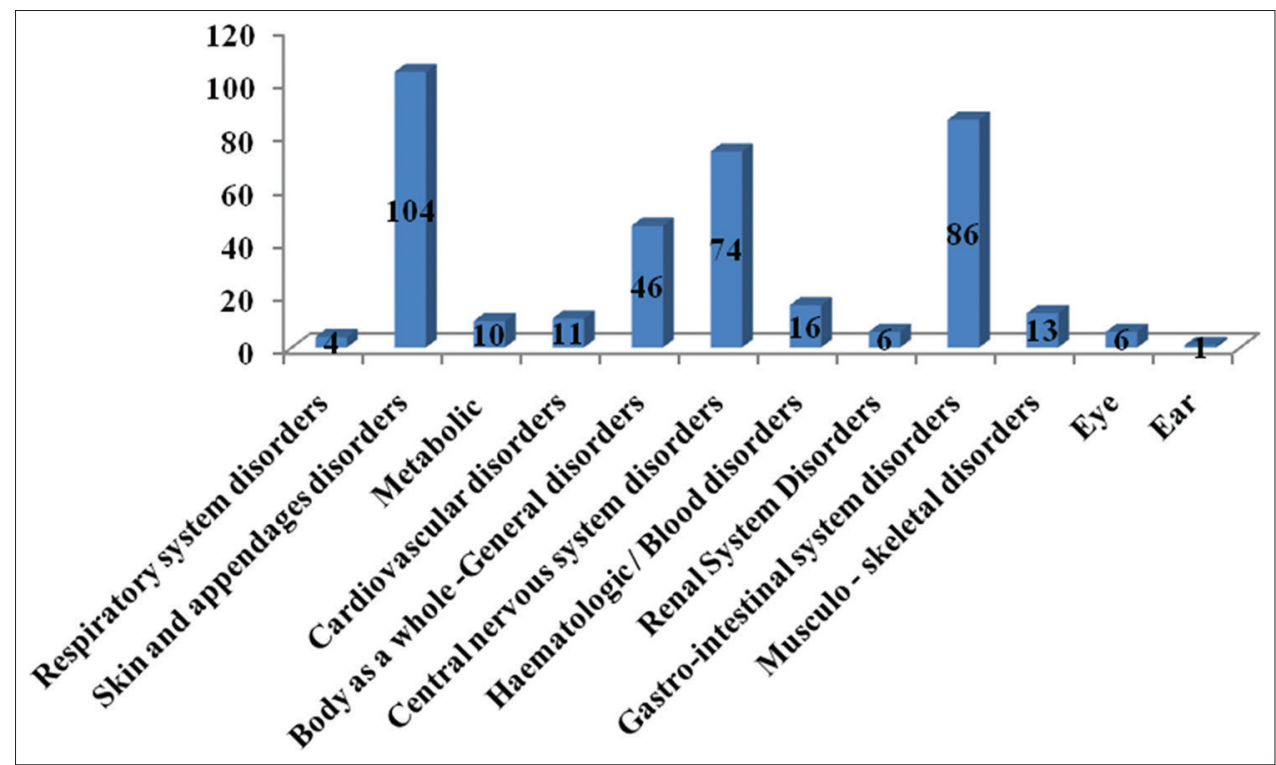

Fig. 3: Organ systems involved in causing adverse drug reactions

Risk factors associated with ADRs

We encountered 83 (22.01\%) cases having associated risk factors. Of these, $30(36.1 \%)$ were alcoholic and 20 (24\%) were smokers as depicted in Table 2.

\section{Causality}

The causality assessment showed that majority of the cases was probable as depicted in Table 3 .

\section{Severity}

The severity of the reactions was classified as mild, moderate, and severe as per modified Hartwig et al. scale as depicted in Table 4.

\section{DISCUSSION}

Females had a higher incidence of ADRs, which are in accordance with many proven previous studies [18], wherein female sex was considered to be a risk factor for the development of ADRs. Women in comparison to men having lower bodyweight and organ size, more body fat, different gastric motility, and lower glomerular filtration rate are attributed by Alomar [19] for having higher ADRs.

Adult group showed a higher percentage of ADRs. This was similar to Venkatesan et al. [20] who also found maximum ADRs among the adult age group. The mean age of the patients developing ADRs was $45.95+17.93$ in their study. However, studies on spontaneous reporting have almost always shown higher incidences in the elderly group [21].
Table 1: Comorbid conditions associated with ADRs

\begin{tabular}{ll}
\hline Comorbid conditions & Number of ADRs \\
\hline Diabetes & 22 \\
Hypertension & 20 \\
Dysthymia & 5 \\
Lymphadenitis & 4 \\
Pregnancy & 3 \\
CRF & 2 \\
S. aureus positive infection & 2 \\
Anemia & 2 \\
Cushing's syndrome & 2 \\
Gastritis & 1 \\
Constipation & 1 \\
Vestibular lesions & 1 \\
Dengue & 1 \\
Hypothyroidism & 1 \\
Urinary tract infection & 1 \\
Pain abdomen & 1 \\
Cholelithiasis, & 1 \\
Fatty liver & 1 \\
Adult polycystic kidney and liver disease & 1 \\
Diabetic nephropathy & 1 \\
Neurocysticercosis & 1 \\
Osteosarcoma of the femur with & 1 \\
lung metastasis & \\
Pleural effusion & 1 \\
\hline
\end{tabular}

S. aureus: Staphylococcus aureus. ADRs: Adverse drug reactions 
Table 2: Risk factors associated with ADRs

\begin{tabular}{ll}
\hline Comorbid conditions & Number of ADRs \\
\hline Alcoholic & 30 \\
Smoker & 20 \\
Known allergy to dust & 12 \\
Similar previous reaction in past & 6 \\
Known allergy to NSAIDs & 6 \\
Known allergy to penicillins & 4 \\
Prone for gastritis & 2 \\
Known allergy to mushroom & 2 \\
Known allergy to norfloxacin, ofloxacin & 1 \\
\hline ADRs: Adverse drug reactions, NSAIDs: Nonsteroidal anti-inflammatory drugs
\end{tabular}

Table 3: Causality assessment of ADRs

\begin{tabular}{ll}
\hline Causality & Number of reports \\
\hline Probable & 224 \\
Possible & 117 \\
Certain & 35 \\
Unlikely & 1 \\
\hline
\end{tabular}

ADRs: Adverse drug reactions

Table 4: Severity assessment of ADRs

\begin{tabular}{lllc}
\hline Category & Levels & Number & Total \\
\hline Mild & Level 1 & 123 & 224 \\
\multirow{2}{*}{ Moderate } & Level 2 & 101 & 123 \\
& Level 3 & 2 & \\
Severe & Level 4A & 121 & 30 \\
& Level 4B & 0 & \\
& Level 5 & 23 & \\
\hline
\end{tabular}

ADRs: Adverse drug reactions

It appears that in voluntary reporting system the ADRs of the adult group may undergo unnoticed and hence unreported.

Antimicrobials $(n=90)$ and anti-cancer group of drugs $(n=75)$ accounted for the higher incidence of ADRs, which are in accordance with the study done by Shah and Sattigeri [22].

The most commonly involved organ was the skin and its appendages, which is in accordance to that reported Bhabhor et al. [23] who reported $52.25 \%$ of skin and appendages disorders in their study. Similar results were observed by Siddiqui et al. [24]. Since these reactions are easily detectable, they seem to be preponderant in any reports on ADRs.

Although polytherapy is supposed to be associated with the increased occurrence of ADRs due to drug interactions, our study had an almost similar number of ADRs with monotherapy as well as with polytherapy.

We encountered 76 reports possessing comorbid conditions. Diabetes and hypertension were the most common comorbid conditions associated. This is found to be associated with higher incidences of ADRs as there is a possibility of drug-drug interactions [25]. It is also observed that adequate control of these conditions will reduce the ADRs of other drugs.

As far as the remedial measures undertaken were concerned, the most common was to stop the offending drug $(n=276)$ and the most common outcome seen was recovery of the patient $(n=212)$. Stopping the offending drug usually helped in the recovery of the patient making the diagnosis of ADRs easier.

The causality assessment of suspected drugs to reactions shown more than half of reactions belonged to probable category, and only

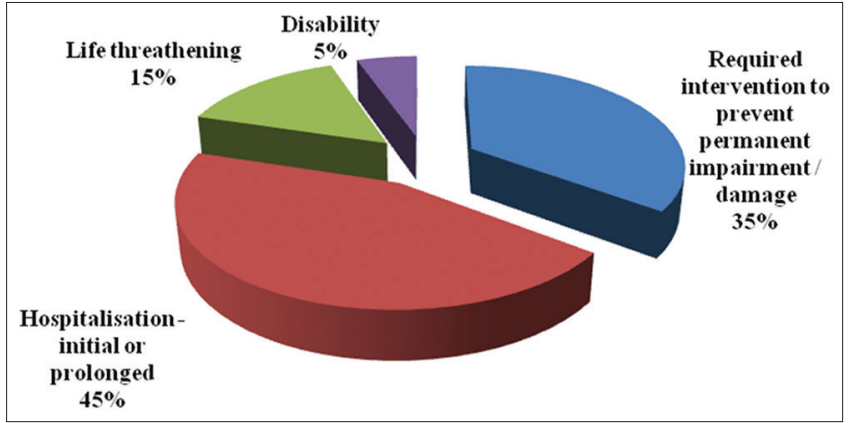

Fig. 4: Reasons for seriousness in adverse drug reactions

a few percentage reactions belonged to certain category, which is in accordance to Kumari et al. [26] and contrast to the previous studies on active surveillance showing maximum of possible causality [5].

With respect to the severity assessment, most of the reactions encountered were of mild grade $(n=224)$ followed by moderate $(n=123)$ and severe $(n=30)$ grades.

Our study had 56 (14.85\%) invalid reports. Validity of the reports could has been increased by collecting and documenting all the details relating to the ADRs. A more complete ADR form would have given higher validity rates.

Through our study, we encountered 97 unexpected reactions. This was possible mainly because of adopting active surveillance as the investigators were aware of the expected reaction. Our study, hence, shows that active surveillance has a better effect on the quality of reporting. Thorough and accurate knowledge of the drug profile on the part of the reporter helps in predicting the various possible ADRs with the usage of the drugs. The detection of the unexpected ADRs will aid in exploring the undetected ADRs that are all possible with the usage of the drugs and add to the existing knowledge about the drugs.

\section{Limitations of our study}

The results of our study are based only the data procured through a smaller population, which, need not depict the results of the general population. Studies on a larger population can reveal a better result.

\section{CONCLUSION}

Spontaneous reporting is the major modality of ADR reporting in our country. However, active surveillance seems to be a better modality to identify the risk factors and detects more unexpected reactions. More awareness about the usefulness and importance about ADR reporting will help in increasing the reporting rate among the physicians and also thus help in better patient management.

\section{CONFLICTS OF INTEREST}

The author(s) declared no potential conflicts of interest with respect to the research, authorship, and/or publication of this article.

\section{AUTHOR'S CONTRIBUTION}

All the authors have equally contributed in the idea of the research; planning and execution of the study protocol; collection, compiling and analysis of the data, and preparing the manuscript.

\section{REFERENCES}

1. Srinivasan R, Ramya G. Adverse drug reaction-causality assessment. Int J Res Pharm Chem 2011;1:606-12.

2. Patil SB, Raikar SR, Bhaskar HN, Janardhan M, Rao VY, Vahila. A study of adverse drug reactions in patients treated with Penicillins in a rural tertiary care hospital. Int J Pharmacol Clin Sci 2016;5:41-4.

3. Lihite RJ, Lahkar M, Das S, Hazarika D, Kotni M, Maqbool M, et al. 
A study on adverse drug reactions in a tertiary care hospital of Northeast India. Alex J Med 2016;53:151-6.

4. Raut A, Modi A, Sumariya R, Surve R, Vohra F, Pawar A. Monitoring of adverse drug reactions in elderly patients in an Indian tertiary care hospital. Res Rev Res Rev J Hosp Clin Pharm 2016;2:14-8.

5. Swamy S, Bhanuprakash, Nadig P, Muralimohan, Shetty M. Profile of suspect adverse drug reactions in a teaching tertiary care Hospital. J Pharmacol Clin Toxicol 2013:1:1005.

6. Doshi MS, Patel PP, Shah SP, Dikshit RK. Intensive monitoring of adverse drug reactions in hospitalized patients of two medical units at a tertiary care teaching hospital. J Pharmacol Pharmacother 2012:3:308-13

7. Bahri C. How India tackles adverse drug reactions-by ignoring data. India Spend 2016. Available from: http:/www.indiaspend.com/ cover-story/how-india-tackles-adverse-drug-reactions-by-ignoringdata-45036.

8. Vijayakumar TM, Dhanaraju MD. Description of adverse drug reactions in a multi-speciality teaching Hospital. Int J Integr Med 2013;1:1-6.

9. Suspected Adverse Reaction Reporting Form for Voluntary Reporting of Adverse Drug Reactions by healthcare professionals. National Coordinating Centre Pharmacovigilance Programme of India. India Pharmacopoeia Commission Ministry of Health \& Family Welfare Government of India. Available from: http://www.ipc.gov.in/PvPI/ ADRReportingForm.pdf.

10. JFDA. Guidelines for Detecting and Reporting Adverse Drug Reactions. Rational Drug Use and Pharmacovigilance Department. JFDA; 2014.

11. Brunton LL. Goodman and Gilman's The Pharmacological Basis of Therapeutics. 12 $2^{\text {th }}$ ed. China: McGraw Hill Medical Company; 2012.

12. Pathak AK, Kumar M, Dokania S, Mohan L, Dikshit H. A retrospective analysis of reporting of adverse drug reactions in a tertiary care teaching hospital: One year survey. J Clin Diagn Res 2016;10:1-4.

13. Uppsala Monitoring Centre. International Monitoring of Adverse Reactions To Drugs. WHO Adverse Reaction Terminology. Uppsala, Sweden: Uppsala Monitoring Centre; 2007.

14. Gupta SK. Textbook of Pharmacovigilance. $1^{\text {st }}$ ed. India: Jaypee Brothers Medical (P) Publishers; 2011.
15. Katzung BG, Masters SB, Trevor AJ. In: Basic and Clinical Pharmacology. $13^{\text {th }}$ ed. New Delhi: Tata McGraw Hill Education Pvt. Ltd; 2012.

16. Naranjo CA, Busto U, Sellers EM, Sandor P, Ruiz I, Roberts EA, et al. A method for estimating the probability of adverse drug reactions. Clin Pharmacol Ther 1981;30:239-45.

17. Hartwig SC, Siegel J, Schneider PJ. Preventability and severity assessment in reporting adverse drug reactions. Am J Hosp Pharm 1992;49:2229-32.

18. Ansari MS, Al-Otaibi F. Drug utilization based ADRS monitoring of antihypertensive agents prescribed in al-quwayiyah general hospital, Saudi Arabia. Int J Pharm Pharm Sci 2018;10:22-6.

19. Alomar MJ. Factors affecting the development of adverse drug reactions (review article). Saudi Pharm J 2014:22:83-94.

20. Venkatesan R, Ravisankar S, Lakshminarasu M, Rajendran SD. Intensive monitoring of adverse drug reaction in hospitalized patients in a South Indian Tertiary Care Hospital. Int J Pharma Ther 2014:5:19-26.

21. Jose J, Rao PG. Pattern of adverse drug reactions notified by spontaneousreporting in an Indian tertiary care teaching hospital. Pharmacol Res 2006:54:226-33

22. Shah J, Sattigeri BM. A study of adverse drug reactions in patients admitted to orthopaedic wards in tertiary care teaching rural hospital. Int J Pharmacol Ther 2013;3:24-30.

23. Bhabhor PH, Patel TK, Vahora R, Patel PB, Desai N. Adverse drug reactions in a tertiary care teaching hospital in India: analysis of spontaneously reported cases. Int $\mathrm{J}$ Basic Clin Pharmacol 2014;3:1078-85

24. Siddiqui S, Baig MM, Jaffer S, Ansari SF. Study on prevalence of adverse drug reactions in patients suffering from tuberculosis in a tertiary care hospital. Int J Pharm Pharm Sci 2016;8:375-7.

25. Triplitt C. Drug interactions of medications commonly used in diabetes. Diabetes Spectrum 2006;19: 202-211

26. Kumari SV, Rani MU, Prasanthi NL. Analytical study of adverse drug reactions reported at adverse drug reaction monitoring centre in a tertiary care teaching hospital in Andhra-Pradesh, India. IOSR J Dent Med Sci 2015;14:47-50. 